Original Research Paper

\title{
A Statistical Model for China's Degree of Foreign Trade Dependence
}

\author{
${ }^{1}$ Wei Yu and ${ }^{2}$ Jusong $Y u$ \\ ${ }^{1}$ School of Mathematical Sciences, Anhui University, Hefei 230601, China \\ ${ }^{2}$ School of Information Engineering, Anhui University, Hefei 230601, China
}

\author{
Article history \\ Received: 12-08-2018 \\ Revised: 19-11-2018 \\ Accepted: 14-01-2019 \\ Corresponding Author: \\ Wei Yu \\ School of Mathematical \\ Sciences, Anhui University, \\ Hefei 230601, China \\ Email: 1249193221@qq.com
}

\begin{abstract}
This study studies China's degree of Foreign Trade Dependence (FTD), which shows a persistent increasing tendency from 1981 to 2009. The speed and scope of its increasing exceed those of many other countries since the practicing of the reform and open policy. One of the reasons we cannot ignore is the rapid development of processing trade. To analyze this influence, we use an exponential model and a quadratic model to analyze some data sets of trade. Finally we result that the processing trade can explain our high FTD to a great extent, but the levels that FTD depends on processing trade are not the same in different periods.
\end{abstract}

Keywords: Processing Trade, Total Amount of Trade, Statistical Analysis, Import Dependence Ratio, Export Dependence Ratio

\section{Introduction}

Degree of Foreign Trade Dependence (FTD) is a criterion that reflects the degree of association between a country or a region and the international market. It is the sum of import dependence ratio (ID) and export dependence ratio (ED), (see Wang, 2005), where:

$$
\begin{aligned}
& \mathrm{ID}=\text { amount of import / GDP } \\
& \mathrm{ED}=\text { amount of export / GDP }
\end{aligned}
$$

Then the value of FTD is:

FTD $=$ (amount of import + amount of export $) /$ GDP

Generally speaking, countries with higher degree of openness markets have higher FTD than those with lower degree of openness markets. FTD is also affected by the economic growth and domestic economic scale. The countries with fast economic growth have a high degree of dependence on imports and countries with large domestic economies have a low degree of dependence. In addition, exchange rate also affects FTD of a country.

Compared with the steady changes of FTD in most countries in the world, China's FTD has been on a continuous rise since the reform and opening up. And the growth rate and range are much higher than those of other countries. During the period 1970-2000, China's FTD has increased nearly 8 times, see Liu (2009). As for the economic significance of high FTD, although developed trade exchanges are a strong driving force to promote the growth of national economy, too high FTD will also pose a threat to the economic security of the country. China may now face such a threat, see references $\mathrm{Li}$ (2010) and $\mathrm{Qu}(2009)$.

Although the FTD is influenced by many factors, the development of processing trade is one of the important reasons leading to the high FTD in China in recent years. Processing trade is that: A country imports raw materials, tools or parts in various ways, uses its own production capacity and technology and then exports into finished products, thus obtaining the additional value embodied in foreign exchange.

Processing trade usually includes two forms: material processing and feed processing. Their specific definitions can be found in $\mathrm{Li}$ and Gao (2010). Cui (2004) pointed out that in the process of international production and flow of processing trade, China is only engaged in some of the low-end processing links. The huge export and trade surplus does not mean that China has obtained corresponding trade benefits in the course of trade. Most of the core technologies are in the hands of foreign institutions.

Therefore studying the processing trade is a significant topic for trade research. Regarding the influence of processing trade on China's FTD, many researchers have done qualitative or quantitative analysis. For example, Liu (2009) concluded that the correlation coefficient between the proportion of processing trade in total import and export trade and the FTD is 0.72 from 1981 to 2007 , showing a significant 
positive correlation. Dai (2010) and Jiang et al. (2010) also concluded that processing trade is the main component of foreign trade dependence. In this paper, an exponential model and a quadratic model are used to fit the changing trend of the total trade volume and the proportion of processing trade, respectively, and the main factors affecting the FTD in different periods are further analyzed.

\section{Data Description and Relevant Studies}

The data set used in this paper are shown in Tables 1 and 2. In Table 1, the data sources of total amount of trade $\left(x_{1}\right)$, GDP $\left(x_{2}\right)$ and exchange rate $\left(x_{3}\right)$ are the website of the National Bureau of Statistics of China and the website of the General Administration of Customs of China. The calculation of FTD $\left(x_{4}\right)$ is that $x_{4}=$ $\left(\mathrm{x}_{1} \times \mathrm{x}_{3} / 100\right) / \mathrm{x}_{2}$. In Table 2 , export $\left(x_{5}\right)$ and import $\left(x_{6}\right)$ in total trade, export $\left(x_{7}\right)$ and import $\left(x_{8}\right)$ in processing trade are from the Statistical Yearbook of China Foreign Trade Statistics (2010). $R_{1}$ means the proportion of processing trade in exports. $R_{2}$ means the proportion of processing trade in imports. $R_{3}$ means the proportion of processing trade in the total import and export volume.

$$
R_{1}=x_{7} / x_{5}, R_{2}=x_{8} / x_{6}, R_{3}=\left(x_{7}+x_{8}\right) /\left(x_{5}+x_{6}\right) .
$$

Some articles have used similar data sets to analyze the FTD. For example, Cui (2004) presented the scatter plots of the processing trade and FTD during 1980 to 2003. They divided the evolution process of China's FTD to four periods. Li (2014) used the import, export and GDP data to calculate the FTD of China during 2003 to 2012 and concluded that the whole trend of China's FTD is slowly decreasing after 2006. Mu et al. (2016) employed the grey relational degree model to analyze the correlation of some factors and FTD using the data in 1978-2014. They found that the correlation coefficient between the proportion of processing trade and FTD is 0.969 . The total import and export volume of processing trade increased from nearly US $\$ 1.7$ billion in 1980 to US $\$ 549.7$ billion in 2004, an increase of more than 320 times. The status of foreign-invested enterprises as the main body of processing trade is even more prominent.

In recent years, the regression model to analyze economic and trade data sets is a commonly used technique. For example, Deng and Li (2014), Guo (2015) and Zhao and Peng (2014) respectively used regression models to study the effect of exchange rate fluctuation, express service industry and technological progress on China's trade. Kan and Lv (2016) studied nonlinear impact of import and export trade on environmental pollution based on a panel smoothing transformation regression Model. However, as far as we know, few studies have constructed non-linear models to fit the FTD or processing trade data sets of China and used the models to analyze the developing trend. In Section 3, we will use an exponential model and a quadratic model to analyze the data sets.

\section{The Statistical Models for Analyzing FTD}

The FTD data in Table 1 are shown as the line chart in Fig. 1. As can be seen, from 1981 to 2009, the changing pattern of China's FTD can be divided to approximately two stages. The first stage is from 1981 to 1994, starting with the opening of China foreign trade market. And the second stage is from 2000 to 2009 , starting with event that China joined the WTO in 2001, the foreign trade has developed rapidly. There have been two short-term declines, one from 1995-1999, due to volatility in general trade caused by currency reform and the Asian financial crisis and a sharp decline in 2009, caused by the economic crisis at that time.

Table 1: The FTD data for China during 1981-2009

\begin{tabular}{lllll}
\hline Year & Total trade (100 million dollars) & GDP $(100$ million yuan) & Exchange rate (yuan: 100 dollars) & FTD \\
\hline 1981 & 440.3 & 4891.6 & 170.51 & 0.153 \\
1983 & 436.2 & 5962.7 & 197.57 & 0.145 \\
1985 & 696.0 & 9016.0 & 293.66 & 0.227 \\
1987 & 826.5 & 12058.6 & 372.21 & 0.255 \\
1989 & 1116.8 & 16692.3 & 376.51 & 0.252 \\
1991 & 1357.0 & 21781.5 & 532.33 & 0.332 \\
1993 & 1957.0 & 35333.9 & 576.20 & 0.319 \\
1995 & 2808.6 & 60793.7 & 835.10 & 0.386 \\
1997 & 3251.6 & 78973.0 & 828.98 & 0.341 \\
1999 & 3606.3 & 89677.1 & 827.83 & 0.333 \\
2001 & 5096.5 & 109655.2 & 827.70 & 0.385 \\
2003 & 8509.9 & 135822.8 & 827.70 & 0.519 \\
2005 & 14219.0 & 183084.8 & 819.17 & 0.636 \\
2007 & 21737.3 & 246619.0 & 730.50 & 0.644 \\
2009 & 22072.7 & 340902.8 & 683.10 & 0.442 \\
\hline
\end{tabular}




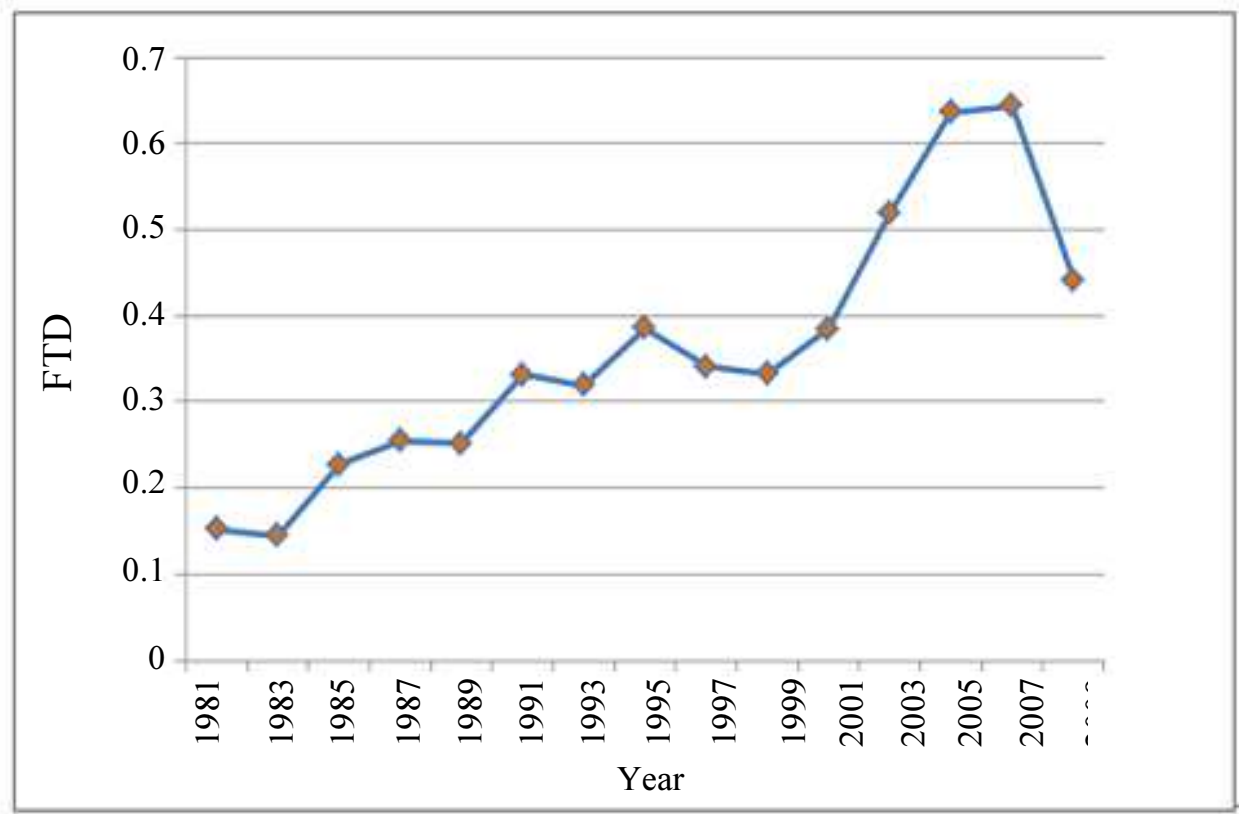

Fig. 1: China's degree of foreign trade dependence during 1981-2009

Table 2: The proportion of processing trade in the total trade volume during 1981-2009

\begin{tabular}{|c|c|c|c|c|c|c|c|}
\hline \multirow[b]{2}{*}{ Year } & \multicolumn{2}{|c|}{$\begin{array}{l}\text { Total trade } \\
\text { (100 million dollars) }\end{array}$} & \multicolumn{2}{|c|}{$\begin{array}{l}\text { Processing trade } \\
\text { (100 million dollars) }\end{array}$} & \multirow[b]{2}{*}{$\mathrm{R}_{1}(\%)$} & \multirow[b]{2}{*}{$\mathrm{R}_{2}(\%)$} & \multirow[b]{2}{*}{$\mathrm{R}_{3}(\%)$} \\
\hline & Export & Import & Export & Import & & & \\
\hline$\overline{1981}$ & 220.10 & 220.20 & 11.31 & 15.04 & 5.14 & 6.83 & 5.98 \\
\hline 1983 & 222.30 & 213.90 & 20.01 & 24.01 & 9.00 & 11.22 & 10.09 \\
\hline 1985 & 273.50 & 422.50 & 33.16 & 42.74 & 12.12 & 10.12 & 10.91 \\
\hline 1987 & 394.40 & 432.10 & 81.38 & 95.02 & 20.63 & 21.99 & 21.34 \\
\hline 1989 & 525.40 & 591.40 & 188.04 & 156.78 & 35.79 & 26.51 & 30.88 \\
\hline 1991 & 719.10 & 637.90 & 324.30 & 250.30 & 45.10 & 39.24 & 42.34 \\
\hline 1993 & 917.40 & 1039.60 & 442.36 & 363.60 & 48.22 & 34.97 & 41.18 \\
\hline 1995 & 1487.80 & 1320.80 & 737.18 & 583.59 & 49.55 & 44.18 & 47.03 \\
\hline 1997 & 1827.90 & 1423.70 & 996.02 & 702.06 & 54.49 & 49.31 & 52.22 \\
\hline 1999 & 1949.30 & 1657.00 & 1108.82 & 735.78 & 56.88 & 44.40 & 51.15 \\
\hline 2001 & 2661.00 & 2435.50 & 1474.34 & 939.74 & 55.41 & 38.59 & 47.37 \\
\hline 2003 & 4382.30 & 4127.60 & 2418.49 & 1629.35 & 55.19 & 39.47 & 47.57 \\
\hline 2005 & 7619.50 & 6599.50 & 4164.67 & 2740.12 & 54.66 & 41.52 & 48.56 \\
\hline 2007 & 12177.80 & 9559.50 & 6175.60 & 3684.75 & 50.71 & 38.55 & 45.36 \\
\hline 2009 & 12016.10 & 10059.20 & 5868.62 & 3222.91 & 48.84 & 32.04 & 41.18 \\
\hline
\end{tabular}

As can be seen from Table 2, processing trade has been a large proportion of total trade and growing rapidly. To analyze the extent to which processing trade affects the FTD, denote $t=1,3, \ldots 29$ as the year of 1981 , $1983, \ldots, 2009$. Taking $t$ as the covariant, the total trade volume $(T)$ and the proportion of processing trade $\left(R_{3}\right)$ in the total trade volume as dependent variables to do regression analysis. The regression models are as follows:

$$
\begin{aligned}
& T=b_{0} b_{1}^{t} e^{\varepsilon} \\
& R_{3}=b_{0}+b_{1} t+b_{2} t^{2}+\varepsilon
\end{aligned}
$$

where, $e^{\varepsilon}$ and $\varepsilon$ are the error terms of the two models respectively. Estimate the parameters by the maximum likelihood method. Tables 3 and 4 show that the determination coefficients ( $\mathrm{R}$ square) of the two models are 0.984 and 0.955 respectively. It can also be seen from Fig. 2 and 3 that the fitting effect of the two models is very good. The final two regression equations are:

$$
\begin{aligned}
& \hat{T}=299.511 \times 1.158^{t}, \\
& \hat{R}_{3}=4.871+5.246 t-0.126 t^{2},
\end{aligned}
$$




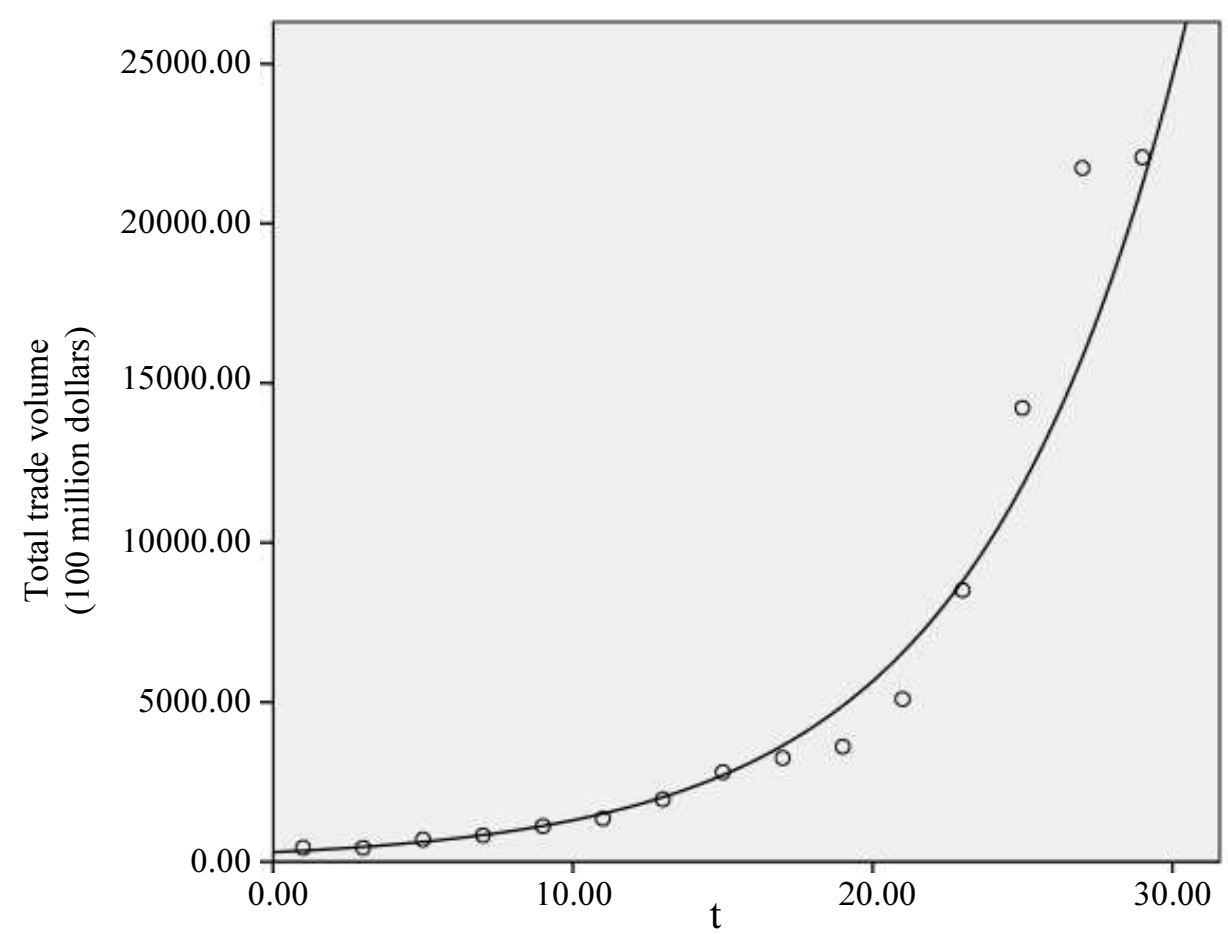

Fig. 2: The fitting curve of China's total trade from 1981 to 2009. The circle is the total volume of import and export trade in each year and the curve is the fitting result corresponding to the model (3.1)

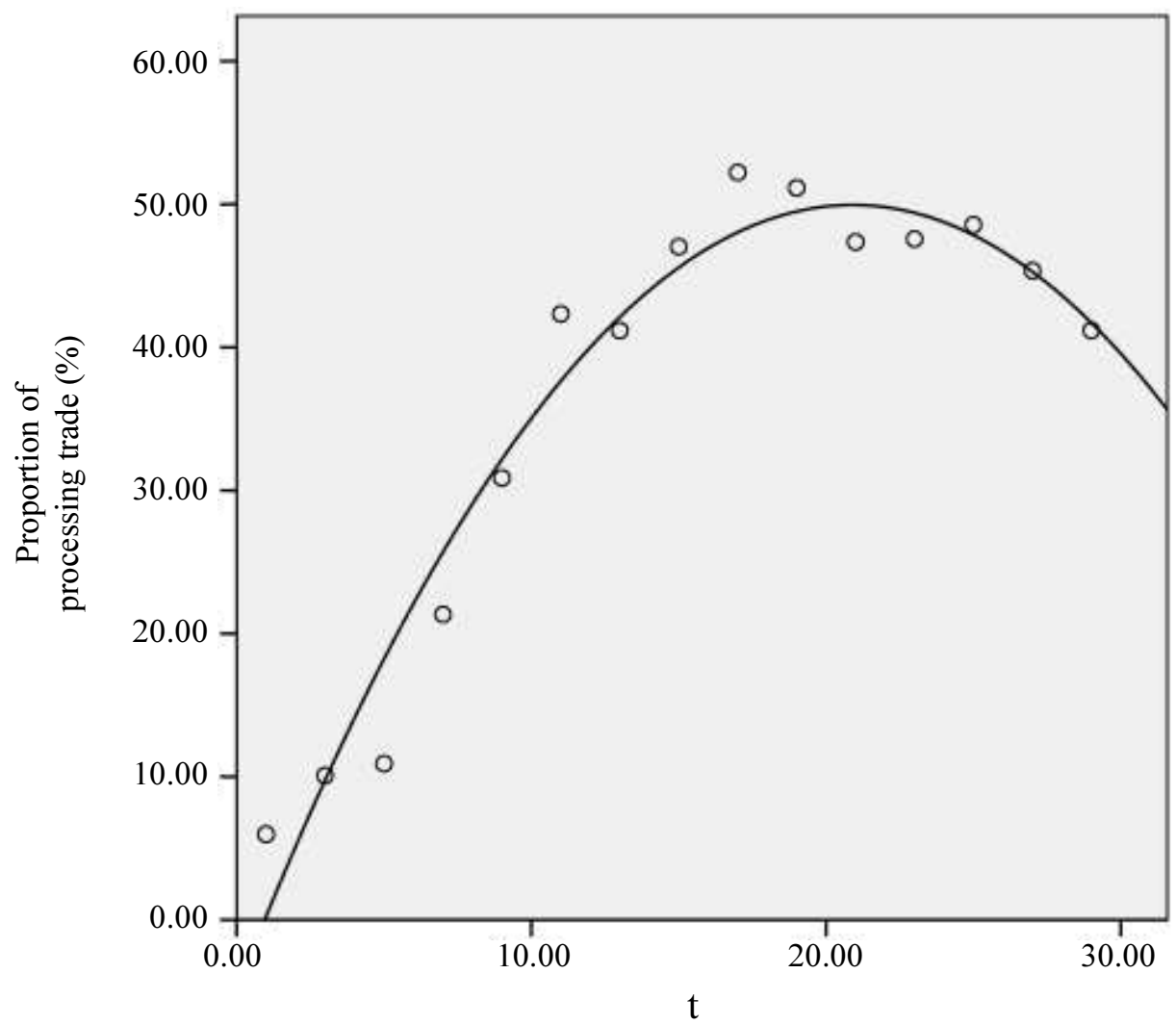

Fig. 3: The fitting curve of China's proportion of processing trade from 1981 to 2009 . The circle is the proportion of processing trade in each year and the curve is the fitting result corresponding to the model (3.2) 
Table 3: Model summary and parameter estimates for model 3.1

Model summary Parameter estimates

\begin{tabular}{lllllll}
\hline R square & $F$ & df1 & df2 & Sig. & $b_{0}$ & $b_{1}$ \\
\hline 0.984 & 800.357 & 1 & 13 & 0.000 & 299.511 & 1.158 \\
\hline
\end{tabular}

Table 4: Model summary and parameter estimates for model 3.2

\begin{tabular}{|c|c|c|c|c|c|}
\hline \multicolumn{3}{|l|}{ Model summary } & \multicolumn{3}{|c|}{ Parameter estimates } \\
\hline $\mathrm{R}$ square $\mathrm{F}$ & df1 df2 & Sig. & $b_{0}$ & $b_{1}$ & $b_{2}$ \\
\hline 128.609 & 12 & 0.000 & -4.871 & 5.246 & -0.126 \\
\hline
\end{tabular}

In this way, the factors affecting the two stages of the rapid growth of China's FTD mentioned above are clear. The total trade volume is increasing exponentially.

The growth rate of China's total trade volume is still relatively slow from 1981 to 1994 , while the proportion of processing trade increased rapidly. At this stage, the increase of FTD is largely caused by the increase in the volume of processing trade. From 2000 to 2009, the growth momentum of total trade is strong and the proportion of processing trade remains stable and decreased slightly. This indicates that the influence of processing trade on FTD is weakened and the rapid increase of FTD is caused by the development of other trade. This also indicates that the industrial structure of China has been greatly improved in the past 30 years. The results of the models coincides with the viewpoint in some existing literatures like $\mathrm{Mu}$ et al. (2016) and $\mathrm{Li}$ (2014), that the status of the primary industries related to processing is declining, while the tertiary industry has been fully developed.

\section{Conclusion}

Through an exponential model and a quadratic model, this paper analyzes the influence factors of China's FTD in the past 30 years. The results show that the influence of processing trade is not as great as that in the early stage of reform and opening up. China's FTD got a peak value of $65.17 \%$ in 2006 and then shows a decreasing trend during recent years. As Li (2014) pointed out, this is because the increase in domestic consumption demand, weakening of comparative advantage of labor-intensive products, falling of output value of processing trade and improvement in the level of manufacturing. In addition, the proportion of China's trade in services has risen obviously in the past ten years. The improvement of China's industrial structure also leads to the slowly decreasing of FTD (Mu et al., 2016). This can also be seen from the models in Section 3.

However, China's FTD is still at a relatively high level, posing a threat to China's economic security. As Guan (2015) pointed out, China's FTD has always been above $40 \%$ in recent years (almost double that of the United States and Japan). The continued high FTD will make China's economy more affected by foreign economic fluctuations. In view of this, it is urgent to change the mode of economic growth and expand domestic demand. In addition, it is imperative to upgrade the transformation of processing trade. Therefore, it is necessary to further optimize the main structure of enterprises, improve the supervision system, strengthen the ability of national brand innovation, give more preferential policies to national enterprises and actively support domestic enterprises.

\section{Acknowledgement}

The authors thank the editor, the associate editor, and referees for their constructive comments that led to an improvement of an early version of the article.

The research described herewith was supported by a grant from Research Fund of Anhui University (No: J01006185).

\section{Author's Contributions}

Wei Yu: Do model construction, data analysis and write the main part.

Jusong Yu: Search for some existing researches and write the introductions.

\section{Ethics}

This article is original and contains unpublished material. The corresponding author confirms that all of the authors have read and approved the manuscript and there are no ethical issues involved.

\section{References}

Cui, D.H., 2004. Analysis and reflection on the China's degree of foreign trade dependence. World Economic Res., 2004: 30-36.

Dai, Q.H., 2010. Study on the causes and solutions of excessive foreign trade dependence in China. Urban Construction, 58: 47-49.

Deng, X.H. and Z.F. Li, 2014. A study on the effect of exchange rate fluctuation on China's trade balanceAnalysis based on vector autoregressive model. Economic Res., 2014: 12-22.

Guan, F.C., 2015. A study on the degree of China's foreign trade dependence. Market Modernization, 2015: 2-3.

Guo, Z.G., 2015. The influence of express service industry on China's international trade based on regression model analysis. Business, 2015: 94-94.

Jiang, X.L., Q. Dai and X. Huang, 2010. An analysis of the causes of China's high degree of foreign trade dependence. Economic Trade Update Mid-Journals. 
Kan, D.X. and L.J. Lv, 2016. Nonlinear impact of import and export trade on environmental pollution-based on panel smoothing transformation regression Model. J. University International Business Economics, 2016: 5-17.

Li, B., 2010. A study on foreign trade degree of dependence and economic security warning. Modern Management Sci.

Li, J.P. and M.X. Gao, 2010. Economic and Social Statistics. Beijing: Renmin University of China Press.

Li, L.L., 2014. Analysis of the reasons for the decline of China's degree of foreign trade dependence in recent years. Market Modernization, 2014: 67-68.

Liu, X.Y., 2009. Processing trade and China's foreign trade degree of dependence. Industrial Technol. Economy, 28: 28-31.

Mu, X.Y., J.L. Ren and K. Liu, 2016. A study on the trend and influencing factors of China's degree of foreign trade dependence. Industrial Economy Rev., 3: 389-396.
Qu, L., 2009. Foreign trade dependence and country comparison and economic risk analysis in China. Academic Theory Series.

Statistical Yearbook of China Foreign Trade Statistics, 2010. China Statistical Yearbook of Foreign Trade and Economic A Airs. Beijing: Statistics Press.

Wang, J.J., 2005. A research on China's degree of dependence on foreign trade. Thesis of Master Degree, Huazhong University of Science and Technology, Wuhan.

Zhao, H. and X. Peng, 2014. An empirical study on the impact of technological progress on the adjustment of China's export trade structure: A regression estimation based on VAR Model. J. Industrial Technological Economics, 252: 87-95. 